1

2

3

\title{
The convergence of cochlear implantation with induced pluripotent
}

\section{stem cell therapy}

Niliksha Gunewardene ${ }^{1}$, Mirella Dottori ${ }^{2,3}$ and Bryony A Nayagam ${ }^{1,3 *}$

1. Department of Otolaryngology, University of Melbourne

2. Department of Pharmacology, University of Melbourne

3. Centre for Neuroscience, University of Melbourne

*Correspondence: Dr Bryony Nayagam, Department of Otolaryngology, Royal Victorian

Eye and Ear Hospital, Level 2, 32 Gisborne Street, East Melbourne, 3002, Australia.

Phone: +61 39929 8385; Fax: +61 39663 1958; e-mail: b.nayagam@unimelb.edu.au

Keywords:

Stem cell, auditory neuron, deafness, differentiation, transplantation, cochlear implant, iPS cell

The manuscript has been prepared in accordance with the Stem Cell Reviews and Reports Guidelines for Authors, and we confirm that the manuscript poses no potential conflicts of interest. 


\section{Introduction}

"Deafness is a misfortune: for it means the loss of the most vital stimulus - the sound of the voice that brings language, sets thoughts astir and keeps us in the intellectual company of man"- Helen Keller. Shifts in lifestyle, an ageing population and reports of a so called "iPod generation" could all be contributing to the surge of people experiencing sensorineural hearing loss. The sensation of hearing is greatly underestimated until it is lost. Ultimately, hearing loss results in a reduced capacity to communicate due to an impaired ability to listen and respond to spoken language. Considering the fundamental role of communication in our society, individuals with an acquired hearing loss may experience reduced educational and vocational opportunities and restricted social interactions. Notably, individuals with a hearing impairment often exhibit signs of depression, withdrawal and insomnia (2) and have a higher incidence of subjective ill health and mental ill health $(3,4)$.

The transmission of sound information to the brain occurs within a small, coiled structure in the inner ear, called the cochlea. The cochlea is embedded within the temporal bone of the skull and its size is disproportionate to the exceptional complexity of its structure and function. Thousands of sensory hair cells located within the cochlea, transmit sound information to the bipolar auditory neurons to which they are connected. Approximately 30,000 auditory neurons innervate the hair cells of the adult human cochlea (5). The loss of sensory hair cells is a major cause of sensorineural hearing loss, and hair cells can be damaged or destroyed as a result of prolonged exposure to loud noise, aminoglycoside antibiotics, or simply as a result of ageing. Hair cell death results in the subsequent retraction of peripheral auditory nerve fibers away from the 
sensory epithelium due to the combined loss of neurochemical stimulation and trophic support normally provided by the hair cells $(6,7)$. Therefore, any damage to the sensory cells of the cochlea causes a disruption in the normal pathway of sound transduction from the inner ear to the brain. Whilst animal models have depicted a clear link between hair cell loss and auditory neuron degeneration (8-10), in human cases, auditory neurons have been shown to survive for longer periods following hair cell loss and peripheral fiber withdrawal from the sensory epithelium $(6,7)$. The exact reasons for this disparity in the rates of auditory neuron degeneration may be due to several factors, including species dependent variables and/or differences in the mode and the severity of the lesion induced.

Unlike individuals with a partial hearing loss who may benefit from hearing aids and sound amplification devices, individuals experiencing severe-to-profound sensorineural hearing loss gain little to no benefit from such devices, due to the irreversible damage to sensory hair cells in the affected cochlea. That is, no amount of sound amplification is effective in improving hearing for these individuals. The only routine clinical treatment for this severe degree of hearing loss is a cochlear implant. This neural prosthesis was first conceived in 1790 by Alessandro Volta using a simple metal rod-50 Volt circuit, which was developed into a complex device comprising an external microphone, speech processor, transmitter and an internal receiver, stimulator, and an array of 22 electrodes which are implanted into the cochlea. The implant is designed to bypass the non-functional component of the damaged auditory system, the hair cells, thereby restoring the pathway of sound transduction to the brain. 
The prime candidates for cochlear implantation have severe-to-profound sensorineural hearing loss (70 dB or worse according to current US Food and Drug Administration guidelines) in both ears, with a functioning auditory nerve, and do not benefit from any kind of hearing aid. Almost all profoundly deaf patients report some benefit after receiving cochlear implants, however the degree of such benefits vary substantially between individuals. This variability is reportedly due to factors including (but not limited to) the duration of deafness prior to implantation (11), age of implantation (12), etiology, and experience with the device (13). Cochlear implant recipients usually have the capacity to communicate effectively using speech, but their open set (novel, standardized) sentence recognition is $60 \%$ or less in the best aided conditions (14). Given the variability of the benefits acquired by individuals using cochlear implants, current research has been directed towards biological improvement (e.g. nerve regeneration) to help improve patients' experience with the device.

Advances in electronics and electrical engineering, surgical techniques and pharmacological agents have all contributed to enhancing the efficacy of the cochlear implant over the past 30 years. Given the importance of auditory neurons in relaying sound information to the brain in both normal hearing and cochlear implant recipients, it is not surprising that there are now several emerging therapies for their ongoing preservation and regeneration. Current research strategies are directed toward both the sustained delivery of neurotrophic molecules into the cochlea, and the potential of gene therapy and cell transplants to restore or replace the degenerating sensory elements after deafness. Considering the often lengthy delay between the loss of hearing and clinical treatment, preservation of the function and population of auditory 
neurons has been identified as important in further improving the benefits derived from a cochlear implant $(15,16)$, and this will be the primary focus of the following discussion.

\title{
2. The correlation between auditory neuron survival and patient outcomes with a cochlear implant
}

In the inner ear, the auditory neurons play a critical role in relaying auditory information from the mechanosensory hair cells to the cochlear nucleus in the brainstem (17). Being the target neurons for the cochlear implant, preservation of the auditory neuron population is the most obvious approach to enhance the efficacy of this electrical device. Though it seems logical that greater numbers of auditory neurons might result in improved outcomes for cochlear implant recipients, this is a controversial topic, and both sides of the argument warrant further consideration.

\begin{abstract}
Animal studies clearly demonstrate a correlation between duration of deafness and auditory neuron loss (18), and morphological analyses have reported demyelination, retraction of peripheral processes and apoptosis of auditory neurons after sensorineural hearing loss (19). These morphological changes are accompanied by reduced electrically evoked compound action potentials (20), reduced electrically evoked auditory brainstem response amplitudes (18), shorter latencies in single nerve fibers (18) and diminished responsiveness of auditory neurons to stimulus currents at high rates of electrical stimulation (21). Additionally, animals deafened for a long period of time ( $>52$ weeks) showed higher auditory thresholds and prolonged absolute refractory periods following electrical stimulation of the auditory nerve, compared to normal
\end{abstract}


hearing and short-term deafened controls (22). Although these animal studies have shown that deafness results in both significant morphological changes and perturbations to auditory nerve fiber responses to intracochlear electrical stimulation, some human studies have shown contrary results.

Interestingly, histological analyses of human temporal bones have reported no correlation between the number of surviving auditory neurons and the degree of sensory cell degeneration following sensorineural hearing loss (23-25). Fayad and colleagues reported no significant difference in auditory neuron survival between implanted and non-implanted (contralateral) cochleae $(n=8)$, despite the absence of both hair cells and peripheral processes in these deaf cochleae (23). Cochlear reconstruction analyses from human temporal bones have also reported that a complete loss of hair cells in the base of the cochlea is not accompanied by a proportional loss of auditory neurons in the modiolar base (24). Whilst absolute numbers examined tend to be low, findings correlating clinical performance history with histological data are understandably appealing, given their potential to help elucidate the importance of auditory neural survival on cochlear implant performance in humans $[n=8$ (23); $n=4(24)]$. Future studies using larger cohorts of subjects will assist in further clarifying this relationship.

\footnotetext{
The conflicting data obtained from human and animal studies could partly be explained by differences in the relative lifespan of auditory neurons in humans and small mammals. For example, human auditory neurons may have a longer lifespan compared to animals due to their clustering propensity. The reduced intercommunication between the neurons with neurites or
} 
other auditory neurons allows for greater trophic support and longer neuronal life span $(26,27)$. Conversely, it could be argued that the shorter life span of auditory neurons in experimental animals compared to humans may account for the faster cellular degeneration seen in animal models (24). Calculation of the time interval between the time of hair cell loss and auditory neuron loss in these animals was a fraction of their life span whereas in humans this degeneration with age does not occur to the same extent or rate $(24,25)$. It is crucial that the differences in physiology and relative life span of auditory neurons in humans verses experimental animals is addressed prior to clinical translation of any auditory neuron replacement/regeneration therapy.

A further difficulty in addressing this controversial question is that clinical studies are unable to provide all the necessary controls in the way the animal studies are able to. More specifically, these clinical studies do not take into account the performance of any given individual, should they have a greater complement of auditory neurons (28). Whilst animal models can provide the appropriate controls for experimentation, they are not human, and the physiological differences between the two (namely the very slow degeneration of the human auditory nerve in comparison to the rapid degeneration observed in experimental animals) may have significant consequences for therapies aiming to improve clinical outcomes for cochlear implant recipients. Of course there are also inevitable differences in counting methodology, fixation methods, and histological processing between studies, and all of these variables may add to the differences observed between animal and human specimens. Collectively, what seems reasonable to propose, is that there are a certain number of auditory neurons that are required for the cochlear implant to function, and whilst unlikely to be the sole determining factor in cochlear implant performance, 
a healthy population of auditory neurons with functional central connections is likely to contribute to improving clinical outcomes with this neural prosthesis.

The varying outcomes with a cochlear implant suggest that exact performance indicators are yet to be elucidated, and considering that patients with cochlear nerve aplasia do not benefit from electrical stimulation, it is likely that numbers of auditory neurons are key (25). It is reasonable to assume then, that a good functional outcome using a cochlear implant is dependent on several factors, including (but not limited to) the density and integrity of auditory neurons along the length of the cochlea, proximity of the cochlear electrodes to the neurons, the delivery of electrical current to the residual population of neurons, and the extent of degeneration of central connections in the central auditory pathway after a long period without auditory input. If the latter was true, the importance of the peripheral elements would be removed altogether. Considering the evidence, it seems likely that the number of surviving auditory neurons plays an important role in the performance of the cochlear implant, however this role is (as yet) unknown and the overall outcomes with this device are likely to be influenced by several other factors.

\section{Stem cell therapy for cochlear implant recipients}

Factors such as the number and integrity of surviving auditory neurons, the health of their central connections, and the proximity of cochlear electrodes to neurons is likely to affect overall performance with a cochlear implant (29). Therefore the use of stem cells to replace the lost auditory neurons and improve their central connections is an approach which may one day be utilized to enhance performance of the cochlear implant, particularly next generation cochlear 
implants. The use of stem cells for cochlear rehabilitation has been investigated by several groups, for both the replacement of hair cells (30-33) and auditory neurons (34-55). The major challenge of stem cell therapy in the cochlea is to replace damaged or lost cells, without disturbing the delicate cochlear architecture or damaging any residual hearing function (56). The success of this therapy will therefore require overcoming several major obstacles including [1] the differentiation of cells into the appropriate phenotype (Fig.1); [2] the precise delivery of cells into their target site in the cochlea (Fig.2); [3] their prolonged survival after transplantation and [4] their ability to form functional and tonotopic central connections $(16,37)$.

Several stem cell types have now been delivered into the inner ear for the replacement of auditory neurons, including bone marrow stem cells $(35,49,57)$, neural stem cells $(31,34,41$, $47,53,55)$ and embryonic stem cells [ESCs; $(34,37,39,40,43,45,46,51,52,54,58)$. In addition, stem or stem-like cells including neural stem cells $(31,53,55)$, olfactory bulb precursor cells $(59,60)$ and dorsal root ganglia $(38,61,62)$ have been used to enhance the survival of endogenous auditory neurons, by means of their secretion of trophic factors and/or their expression of a supportive protein matrix. Whilst appealing for promoting auditory neural survival, the following discussion will be focused on auditory neural replacement, including techniques used to derive auditory neurons from human embryonic stem cells (hESCs) and how these may be applied to induced pluripotent stem cells (iPS cells) for neural replacement strategies in the deaf cochlea.

\section{Directed differentiation of stem cells into auditory neurons}


There are four main stages involved in neural differentiation: neural induction, expansion, maintenance of neural progenitor stem cells and their differentiation into neurons and glia. The most essential step is identifying and replicating the intrinsic and extrinsic factors which determine cell fate choice to attain the specific phenotype of interest for stem cell transplantation. It is proposed that by mimicking normal auditory developmental conditions and applying the essential cues, stem cells may be induced to differentiate into auditory neurons (63).

\subsection{Normal development of auditory neurons in situ}

In order to successfully differentiate stem cells into an auditory neural lineage, we need to consider their differentiation during development (Fig.1). The sensory auditory neurons of the cochlea, or spiral ganglion neurons as they are more technically termed, arise from the otic placode during development. This specialized cranial placode develops from a thickening of the ectoderm (posterior placodal region or Pax2-positive precursor domain) in the dorsal hindbrain, which invaginates to form individual, more specialized placodes (64). Diversification of the thickened posterior placodal area into individual placodes comprised of pseudostratified epithelia, is induced by activation of the fibroblast growth factor signaling pathway, followed by Wingless (Wnt) and bone morphogenetic protein (BMP) signaling (65). These inductive cues which are intrinsically programmed during development are pivotal for the formation of specialized regions to generate the appropriate cell types. All sensory cells including hair cells, auditory neurons, vestibular neurons and supporting cells that comprise the inner ear are derived from the otic placode via a number of timed interactions and defined differentiation steps. 
Invagination of the otic placode results in the formation of an enclosed spherical region known as the otic vesicle, which develops in close proximity to the hindbrain and notochord (66). The patterning of the otic vesicle is established by the formation of anterior-posterior and dorsoventral axes during development $(67,68)$. The non-sensory posterior region is marked by the expression of $\operatorname{Tbx} 1(69,70)$ and $\operatorname{Lmx} 1 \mathrm{a}(71,72)$ whilst the pro-neurosensory anterior region is marked by the expression of Lunatic fringe [Lfng; $(73)]$, Sox2 $(74,75)$ and Eya1 (76). The proneurosensory region is further subdivided into a neurogenic and pro-sensory region which divides the cell lineage towards either auditory or vestibular neurons, or hair cells and supporting cells (77-79).

Similar to many other neural systems, the development of the inner ear is regulated by local expression of defined transcription factors and basic helix-loop-helix proteins which are crucial for neural differentiation (80). More specifically, the expression of the basic helix-loop-helix gene Neurogenin-1 (Neurog1) in auditory neuronal precursors has been shown to be the earliest event in the generation of auditory neurons $(46,77,81)$. This is followed by the expression of NeuroD1, Brn3a, and GATA3, before these precursors delaminate away from the otic placode $[(46,77,80,82-87) ;$ Figure 1]. It is likely that an interaction between these factors influences the specification of distinct cell types in the cochlea; for example, Sox 2 is reported to interface directly with Eya1 in the pro-neurosensory domain, and influence precursor cells towards either a neural or sensory lineage by upregulating the expression of Atohl $(74,88)$. Continued expression of Sox 2 has been shown to upregulate NeuroD1 and antagonise Atohl, therefore implicating mutual exclusivity of the mechanosensory and neural lineage differentiation process $(78,89,90)$. Clearly, timing is a critical factor in auditory neurosensory cell specification and 
this may be difficult to mimic precisely in vitro, therefore it needs to be carefully addressed when designing different experiments.

Importantly, the mammalian cochlea contains two subtypes of auditory neurons and these have different functional roles and apparent differences in anatomy (17). Type I auditory neurons are bipolar, myelinated and comprise nearly $90 \%$ of the total auditory neuron population. Comparatively, Type II auditory neurons are bipolar, smaller and unmyelinated (17). The afferents of Type I auditory neurons converge on inner hair cells whereas the Type II auditory neurons diverge on outer hair cells. As Type I neurons are the primary neurons for the conversion of sound information to electrical signals in the brain, replacement of these neurons is the most obvious approach to enhance cochlear implant efficacy.

Several approaches have been undertaken by researchers to differentiate hESCs and iPS cells into an auditory neural lineage in vitro prior to transplantation, and these will be discussed in detail below.

\subsection{Challenges for stem cell differentiation into auditory neurons}

One of the most challenging aspects for auditory neural replacement therapy is the lack of a single specific marker which can be used to identify auditory neurons. As such, auditory neurons are often characterized by their bipolar morphology and a cohort of known markers, such as those described in Figure 1. Whilst immunochemical labeling is the standard way to 
characterize this cell phenotype, it is possible that a similar (but not identical) population of neurons could be identified using this method. There is therefore a need to consider further methods of characterization, for example electrophysiological and membrane properties, to determine an auditory neural phenotype. Moreover, it will eventually be important to distinguish between Types I and II stem cell-derived auditory neurons, and these two populations can be separately identified by their expression of peripherin (91) or RT-97 (92), which are exclusively expressed in type II auditory neurons in the mature cochlea. Another recently identified marker for Type II auditory neurons is Prox1, which is expressed during inner ear development and has a role in directing the outgrowth of Type II neuronal fibers (93). As our knowledge of auditory development continues to expand using both molecular profiling (94) and detailed electrophysiological approaches (95), we will undoubtedly have access to further cell-specific

markers. Ideally we would one day gain access to a single auditory neuron-specific marker, thereby facilitating more thorough characterization of differentiated stem cell phenotypes via different induction protocols.

\subsection{Differentiation of human stem cells into auditory-like neurons in vitro}

To date, there have been several reports describing the directed differentiation of murine ESCs into auditory-like neurons $(42,46,63,96,97)$ but few studies have focused on human stem cells $(52,98)$. A recent study conducted by Chen and colleagues, examined a population of human fetal auditory stem cells (characterized by their expression of Oct4 and Sox2) for their potential to differentiate into auditory neurons in vitro (98). The cells were dissociated using trypsin and neuronal differentiation induced by treatment with different combinations of growth factors such 
as basic fibroblast growth factor, epidermal growth factor, and insulin-like growth factor. Combined treatment with sonic hedgehog and basic fibroblast growth factor was reported to be the most efficient to induce neuronal differentiation in these adherent cultures. The neurons obtained in this manner expressed NeuroD1, Brn3a, $\beta$-tubulin III, Neurofilament 200 and Parvalbumin and showed similarities in their electrophysiological properties to Type I auditory neurons (98). The use of human fetal auditory stem cells for differentiation into auditory neurons is a novel and efficient approach. As the cells are already predestined towards an auditory lineage, recapitulation of the steps of development can be achieved more efficiently. However it should be noted that these cells are limited in their supply for cell replacement, and issues relating to mismatches between donor-host tissue would need resolving before these cells could be used clinically.

Human ESCs and iPS cells are more accessible compared to fetal-auditory stem cells, however their pluripotency poses a greater challenge for their specific differentiation to auditory neuronal lineages. Culturing hESCs cells with varying combinations of growth factors and proteins has been shown to produce functional auditory-like neurons which can be expanded in vitro prior to transplantation $(52,98)$. For example, addition of BMP4 to neural progenitors derived from hESCs was shown to produce sensory neurons (52). A cohort of markers was used to analyze differentiated hESCs in these experiments, including the early markers NeuroD1, Brn3a, GATA3 and Ntrk2/3. This study was notable given it was the first to convincingly show the capacity of hESCs to be converted to auditory-like sensory neurons (52). In addition, the authors reported the presence of synapsin-positive contacts between hESC-derived neurons and hair cells when these two cell types were co-cultured in vitro, demonstrating their potential for 
synaptic reconnection. Similar work using mouse ESCs treated with retinoic acid and BMP4 illustrated that greater numbers of sensory-like neurons were produced in comparison to controls, as evidenced by greater expression of peripherin, NTrk2 and $\beta$ III tubulin proteins after a total of 16 days in culture. This further supports a role for BMP4 in directing the differentiation of specified neural precursors toward a sensory neural fate (96).

As already noted, auditory neurons are derived from the otic placode and to date there are no published differentiation protocols which have shown the derivation of placode-like cells from ESCs. An alternative method of deriving auditory neurons in vitro may be achieved by manipulating cell culture protocols designed to produce similar cell populations, for example neural crest precursors (99). There have been several studies published which have shown efficient generation of crest-like progenitors from hESCs (100-103), and both crest and auditory neural progenitors share common molecular and phenotypic profiles during development, including some common genes required for their specification such as Sox9 $(104,105)$, Brn3a $(106,107)$ and NTrk 2/3 (108-114). Given their close association during development, these cultures may already contain auditory-like precursors, which may be enriched for using combinations of relevant proteins (like the BMPs) and small molecules.

\footnotetext{
In summary, neural specification towards a specific cell lineage needs to be precisely controlled by ensuring the appropriate mitogen concentrations are applied at the precise time and mimicking the precise patterning signals during embryonic development. Translation of these findings from hESCs to iPS cells, will represent the next era in stem cell science.
} 


\subsection{Differentiation of human iPS cells into auditory like neurons in vitro}

Although ESCs have received much attention due to their capacity to differentiate into any cell type, the discovery of iPS cells which could be patient-matched and bypass the need for immune-suppression, has triggered excitement in the field of stem cell therapy (115). In addition, iPS cells are not limited by the ethical constraints associated with the use of hESC lines. Induced pluripotent stem cells were first produced by reprogramming mouse fibroblasts, through transgenic expression of critical pluripotent transcription factors such as Oct3/4, Sox3, c-Myc and Klf4 under ESC culture conditions (115-118). Preliminary results have shown that iPS cells behave in a similar manner to hESCs, and importantly, are electrically active following neural induction (119). There is therefore an opportunity to investigate the potential of iPS cells to repair damaged systems, and the auditory system is one for which this new cell therapy may be considered. The availability of iPS cells is unlimited and they have the potential to be manipulated in vitro to obtain cells of the required lineage. Importantly they can be patientmatched, thereby averting the problem of immune rejection and have the capacity of being produced on a large scale.

To date, there is one published report describing the differentiation of mouse iPS cells towards an auditory neural lineage (48). In this study, iPS cells were derived from mouse tail skin fibroblasts by retroviral transduction of Klf3, Oct3 and Sox2. Neural induction was then achieved by co-culturing the iPS cells on a feeder layer of bone marrow-derived PA6, initially described by Kawasaki and colleagues (120). Following neural induction, iPS cell-derived 
neural progenitors were co-cultured with mouse cochlear explants to assess their ability to form synapses with hair cells. The authors observed iPS cell-derived neurites extending towards auditory hair cells, and these processes expressed synapsin, indicating their potential to make pre-synaptic terminals. The iPS cell-derived neural progenitors were transplanted into the mouse cochleae, and although $\sim 50 \%$ of donor cells survived after one week of transplantation, only $2.3 \%$ of the iPS cell-derived neurons expressed VGLUT1, a glutamergic neural marker and a characteristic feature of both auditory and vestibular cochlear neurons (Fig.1). Whilst these findings are promising for possible iPS cell therapy within the cochlea, the molecular basis and neural inducing factors provided by PA6 stromal cells still requires further investigation. A more thorough characterization of several auditory neural markers and electrophysiological properties is therefore warranted in future experimentation (48).

\section{Challenges for stem cell transplantation in the cochlea}

\subsection{Optimizing stem cell survival following transplantation into the deaf cochlea}

The obvious major challenge for combined stem cell therapy with a cochlear implant involves optimizing transplanted cell survival in the inner ear to promote functional recovery. Improving the numbers of stem cell-derived neurons in the cochlea may be achieved by selecting the most appropriate route, site of cell delivery and identifying the stage of differentiation at which cells should be delivered in vivo. In previous studies, exogenous stem cells have reportedly survived in the inner ear for periods of between 3-13 weeks, following their delivery into the scala tympani $(38,39,41,42)$. Whilst cell survival was reported, only limited numbers of cells were detected within the target site, Rosenthal's canal, following delivery into the scala tympani 
(121). As such, more recent transplantation techniques for auditory nerve regeneration have focused on the delivery of cells directly into the modiolus $(35,55,58)$ or auditory nerve $(34,43$, $50,51,122)$. Whilst a more difficult and potentially damaging surgical approach, it confers the additional benefit of providing a three dimensional microenvironment which facilitates further cell growth and differentiation following transplantation, compared to the fluid-filled scala tympani. A summary of these approaches is illustrated in Figure 2.

The stage of differentiation at which stem cells are transplanted into the cochlea is also likely to have an effect on their long term survival and integration into the endogenous auditory system. Generally speaking, there are two broad approaches that have been investigated in terms of the differentiation status of stem cells delivered into the cochlea for neural replacement. The first describes the transplantation of cells completely differentiated in vitro to a neural phenotype. The main advantage of this approach is the ability to manipulate and monitor the differentiation of stem cells, thereby ensuring a high population of neurons can be transplanted. In a recent study, NeuroDl expression was induced in mouse ESCs followed by culturing the cells in GDNF and BDNF prior to transplantation (46). It was illustrated in these experiments that cells differentiated in this manner prior to transplantation, were capable of survival in the deafened mammalian cochleae. In addition, a small percentage of transplanted cells were found to be glutamatergic, the same neurotransmitter phenotype which is expressed in mature auditory neurons. The study reiterated a primary challenge in this field, which is to ascertain whether the neurons generated are both auditory in phenotype and also functional in nature (46). 
Transplantation of partially differentiated stem cells or committed progenitors into the inner ear is a second approach that has been investigated. This technique may be advantageous as stem cells are exposed to endogenous cues from the cochlea. In addition, growth factors and other supportive molecules can be applied in vivo allowing growth of undifferentiated stem cells and promoting integration into the new environment. However in this case, it needs to be noted that individual variability in cochlear pathology will influence the differentiation process of cells and may exert varying effects on their functionality. Moreover, this strategy is built on the presumption that cues from the cochlear environment are sufficient to direct undifferentiated cells into functional auditory neurons, which may not always be the case in a fully developed (adult) and deaf cochlea. This observation is supported by findings illustrating that implantation of a heterogeneous mix of cells showed greater survival in cochleae treated early post injury, compared to late (45). More generally, the study highlighted the importance of the timing of cell implantation in optimizing stem cell survival in vivo.

\begin{abstract}
As most of the stem cells used to date have not been of an otic origin, some researchers have focused their attention on stem cells obtained from fetal cochleae $(98,123)$ or cochlear neuroblasts $(97,124)$ derived from embryos. The otic origin of these cells means that they possess the intrinsic capacity to differentiate into either auditory neural- or hair cell-like cells. Whilst promising in terms of both drug toxicity assays and normal development, the clinical translation of these findings could be difficult due to a limited availability of these cells for transplantation and their likely requirement for ongoing immune-suppression. Nonetheless such experimentation could provide proof-of-principle data to support the feasibility of developing
\end{abstract}


cell-based therapies in the cochlea, and iPS cells could later provide an ongoing source of replacement cells that are not rejected.

\begin{abstract}
As described previously, PA6-treated mouse iPS cells transplanted into mouse cochlea were shown to functionally integrate and differentiate into auditory-like neurons (48). However, it needs to be noted that these cells were transplanted into animals with normal hearing; therefore the impact of cochlear pathology and functionality of the auditory-like neurons formed requires further investigation in a clinically relevant model (48). The differentiation of iPS cells into committed auditory neural progenitors is desirable, as it potentially permits in vivo differentiation and integration, whilst minimizing the risk of tumor formation (48). Notably, post-mitotic (committed) precursors have shown better integration, differentiation and synaptic connectivity following their transplantation into the adult retina, in comparison to proliferating progenitors or stem cells (125). This study highlights the importance of identifying the optimal stage of differentiation for donor cells, in order to facilitate functional integration into the damaged nervous system.
\end{abstract}

\title{
5.2 Developing delivery strategies to preserve endogenous neurons
}

Delivery of cells into the cochlea has proven to be very difficult as it requires accurate surgical precision to avoid damaging the intracochlear structure and jeopardizing residual hearing. As noted earlier, the routes for cell delivery into the cochlea include injection into the fluid filled scala tympani $(38,39,41,42)$, the central modiolus $(35,55,58)$, the auditory nerve $(34,43,50$, $51,122)$ or directly into the target site Rosenthal's canal $[(35,45,121,126)$; Fig.2]. Delivery of cells into the scala tympani via a cochleostomy in the vicinity of the round window during 
cochlear implantation was originally the most frequently used delivery route. Though complimentary in terms of cochlear implant surgery, this delivery technique results in widespread dispersal of transplanted cells throughout the cochlea and to regions distal to the target site (39). Alternatively, the modiolar approach gives direct access to the neural elements of the cochlea, but this approach tends to induce a more vigorous tissue response as it may involve perforating the thin bony modiolar wall inside the cochlea. If not performed correctly, it can also cause damage to the auditory nerve, which is most undesirable. Finally, a few studies have delivered stem cells direct into the Rosenthal's canal $(35,45,121)$. Whilst surgically challenging, this approach offers a more targeted strategy to replace the neurons in the base of the cochlea. The drawback is similar to the modiolar approach in that the technique involves the perforation of the bony modiolus, and consequentially initiating an inflammatory tissue response, and potentially further loss of auditory neurons (126). A small number of transplanted cells can also be found in the scala tympani following this approach $(45,121)$. Collectively, these data indicate the importance of developing an accessible and non-invasive route for stem cell delivery to access the auditory nerve, before this therapy could be implemented clinically.

\subsection{Functional connectivity of transplanted stem cells}

Potentially the most challenging issue awaiting resolution is whether stem cells co-transplanted with cochlear implants can morphologically and functionally integrate into the deafened cochlear environment to improve hearing. The formation of functional synapses between implanted stem cell-derived neurons and cochlear nucleus neurons is crucial for meaningful auditory processing. Interestingly, abnormalities in synaptic ultra-structure have been described 
in brainstem of the congenitally deaf mammalian cochlea, specifically at the large axosomatic endings of myelinated auditory nerve fibers, also known as endbulbs of Held (127). Expanded post-synaptic densities, reduced synaptic vesicles and branching have been observed in endbulbs of these animals, resulting in disrupted synaptic transmission (127). Importantly, these ultrastructural changes were observed to be reversible following electrical stimulation from a cochlear implant (128); however, this synaptic plasticity was not observed in ototoxically deafened animals treated in the same manner even though the post-synaptic density size was preserved (129). Moreover, restoration of the tonotopic mapping of the auditory cortex is observed in neonatally deafened animals receiving electrical stimulation from a cochlear implant. A subsequent study has shown that electrical stimulation from cochlear implants restores afferent inputs from auditory neurons towards the tonotopically organized primary auditory cortex in deafened animals (130). In summary, these data illustrate the positive influences of chronic electrical stimulation in the cochlea in terms of synaptic reorganization, particularly its influence on neuron fibre direction and synaptic patterning. In order to develop this into a beneficial therapy for hearing loss, central connectivity of stem cell-derived neurons will need to be thoroughly investigated, in order for patients to receive perceptual benefits.

\section{6. "Bench to the bedside" - clinical considerations for using human stem cells in an auditory neuron replacement therapy}

The possibility of combining cochlear implants with stem cell-derived neurons offers the possibility of expanding the number of patients that can gain benefits from this prosthetic device. Though data from research studies using hESCs or iPS cells for cell replacement 
therapies have been encouraging, numerous considerations need to be made prior to their translation to the clinic.

Perhaps the greatest drawback of using hESCs in a clinical environment relates to the ethical implications underlying their derivation. Additionally, hESCs are subject to immune responses which may lead to their rejection by the host (131). Though immunosuppressive therapy can counteract $\mathrm{hESC}$ rejection, it compromises the host's ability to combat opportunistic infections, and may have side effects including kidney failure, osteoporosis, diabetes, and hypertension (131). Both hESCs and iPS cells also have the potential to induce formation of teratomas; however, it has been suggested that identification of the "ideal" stage of stem cell differentiation at implantation and microenvironmental cues from the host which promote cell survival could reduce the risk of tumor formation (132-134). It has been implied that the cues necessary for tumor formation varies between individuals, hence transplantation of stem cells during the "optimal" therapeutic time window is pivotal to avoid teratoma formation (133). In summary, the ethical complications and possibility of immune rejection using hESCs, present a window of opportunity for iPS cells to become the cell type of choice for neural replacement strategies, as long as they can be successfully manipulated.

Individualized stem cell based therapy is one of the latest advances in regenerative medicine. Although both embryonic and adult stem cell types have already been delivered into the mammalian cochlea to replace auditory neurons, iPS cells are particularly appealing due to their autologous nature and non immunogenic properties, which distinguishes them from other stem 
cell types. It has been shown that iPS cells have the capacity to differentiate and functionally integrate into the host environment, hence their use is highly desirable therapeutically (48). The ability to directly differentiate a patient's own cells to a desired lineage and then transplant these cells to restore function (without evoking an immune response) is understandably attractive. However, it's translation as a routine clinical application needs further development and refinement, due to the safety and technical complications which require careful consideration. The foremost concern prior to widespread application of any medical technique is patient's safety. The risk of iPS cell-derived cells triggering tumorigenicity (possibly malignant) upon transplantation may outweigh the benefits of using stem cell therapy for hearing loss. This is particularly true considering hearing loss is not a fatal condition, therefore any therapy must result in improvements for the patient.

Given the relatively new nature of iPS cell therapy, there is currently no efficient and routine procedure for the generation of auditory neurons. The main requisite prior to medical application of iPS cells is the implementation of a standardized systematic protocol for the generation of a rigorously characterized stem cell line which is safe for clinical application. It needs to be noted that there is great variability in the behavior of different iPS cell lines, even when produced from the same individual. Additionally, there are differences between ESCs and iPS cells in terms of their responsiveness to environmental cues. Therefore further analysis of these differences needs to be taken into account prior to the clinical application of iPS cells.

The ideal attributes of iPS cells for clinical use include production without integrating vectors, pre-differentiation to the required lineage to avoid teratomas, ability to differentiate to an 
appropriate lineage with high specificity in vitro, and functional integration after transplantation. In a recent study, it was reported that iPS cells retain a transient epigenetic memory of their somatic cell of origin which could influence their differentiation potential (135). Therefore, further assessment of the impact of the retained transient epigenetic memory of the iPS cell's somatic cell of origin should be considered in the development of a clinical therapy. Additionally, iPS cells need to be screened to identify pre-existing genetic and epigenetic abnormalities or mutations that may have arisen from their reprogramming, and which may initiate undesirable side effects post-transplantation (136).

Though it is advantageous to obtain patient specific or allogenic iPS cells, its feasibility in the clinic needs further development due to the length of time required for cell isolation, the high cost, and the technical challenges involved in genetically manipulating these cells. Therefore the future of iPS cell production requires a high-tech but cost effective technology, which has the capacity to generate clinical grade iPS cells of the required cell lineage on an industrial scale. Given these considerations, large-scale cell banks are being developed for iPS cell therapies in future and this may prove a more clinically feasible option, should large numbers of cell lines be developed (137).

Finally, it should be noted that all studies to date have been conducted in animal models, therefore differences between human and animal physiology need to be accounted for. Further studies comparing human iPS cell lines are required to establish the conditions required for their successful differentiation and engraftment into the deafened cochlea. To date there are no 
published accounts of combined stem cell/ cochlear implantation in animal models of deafness, and such studies will be essential in terms of developing this technology for its clinical use in the future. 


\section{Acknowledgements}

The authors would like to extend their thanks to Dr Karina Needham and to the Reviewers, whose constructive feedback greatly improved this review. We acknowledge generous financial support from the National Health and Medical Research Council of Australia, The Garnett Passe and Rodney Williams Memorial Foundation, The Royal Victorian Eye and Ear Hospital, and the Freidrich Ataxia Research Association (USA and Australasia). 


\section{Figure legend}

Figure 1. Differentiation of auditory neurons. Auditory neurons are derived from a single placodal precursor, which is sequentially specialized into otic progenitors and then auditory neural precursors via a series of cell lineage decisions. Each stage of differentiation can be characterized by the expression of a cohort of different markers, as illustrated.

\section{Figure 2. Transplantation of stem cells into the cochlea for neuronal/nerve replacement.}

Transverse histological sections through the mammalian cochlea stained with hematoxylin and eosin (A-C), demonstrating three major stem cell transplantation routes. Stem cells are shown in green to illustrate the expression of green fluorescent protein in many transplanted cell lines. A) Stem cells are delivered directly into the scala tympani (ST), either via the round window or via a cochleostomy. Stem cells delivered using this approach results in cells lining the walls of the ST and scala vestibuli (SV), which are inter-connected at the apex of the cochlea. B) Stem cells delivered directly into their target site, Rosenthal's canal (RC); stem cells are characteristically located within both the ST and RC using this approach. C) Stem cells transplanted into the auditory nerve (AN) or modiolus, which connects the cochlea to the brain. SM: scala media, CI: cochlear implant electrode array. Drawing not to scale. 


\section{References}

1. Statistics about Hearing, Balance, Ear Infections, and Deafness. (2010). National Institute on Deafness and Other Communication Disorders $7 / 6 / 2010$

Available at: http://www.nidcd.nih.gov/about/learn/mission.html.

2. Werngren-Elgstrom, M., Dehlin, O., Iwarsson, S. (2003). Aspects of quality of life in persons with pre-lingual deafness using sign language: subjective wellbeing, ill-health symptoms, depression and insomnia. Archives of Gerontology and Geriatrics, 37(1), 13-24.

3. Van Oyen, H., Tafforeau, J., Demarest, S. (2001). The impact of hearing disability on well-being and health. Sozial- und Praventivmedizin, 46(5), 335-43.

4. de Graaf, R., Bijl, RV. (2002). Determinants of mental distress in adults with a severe auditory impairment: differences between prelingual and postlingual deafness. Psychosomatic Medicine, 64(1), 61-70.

5. Brackmann, DE. (1976). The cochlear implant; basic principles. Laryngoscope, 86(3), 373-88.

6. Spoendlin, H., Schrott, A. (1989). Analysis of the human auditory nerve. Hearing Research, 43(1), 25-38.

7. Bichler, E., Spoendlin, H., Rauchegger, H. (1983). Degeneration of cochlear neurons after amikacin intoxication in the rat. Archives of Oto-Rhino-Laryngology, 237(3), 201-8.

8. Leake, PA., Hradek, GT. (1988). Cochlear pathology of long term neomycin induced deafness in cats. Hearing Research, 33(1), 11-33.

9. Webster, M., Webster, DB. (1981). Spiral ganglion neuron loss following organ of Corti loss: a quantitative study. Brain Research, 212(1), 17-30.

10. Otte, J., Schunknecht, HF., Kerr, AG. (1978). Ganglion cell populations in normal and pathological human cochleae. Implications for cochlear implantation. Laryngoscope, 88(8 Pt 1), 1231-46.

11. Kileny, PR., Zimmerman-Phillips, S., Kemink, JL., Schmaltz, SP. (1991). Effects of preoperative electrical stimulability and historical factors on performance with multichannel cochlear implant. Annals of Otology, Rhinology and Laryngology, 100(7), 563-8.

12. James, D., Rajput, K., Brinton, J., Goswami, U. (2008). Phonological awareness, vocabulary, and word reading in children who use cochlear implants: does age of implantation explain individual variability in performance outcomes and growth? J Deaf Stud Deaf Educ, 13(1), 117-37.

13. Blamey, P., Arndt, P., Bergeron, F., Bredberg, G., Brimacombe, J., Facer, G., Larky, J., Lindstrom, B., Nedzelski, J., Peterson, A., Shipp, D., Staller, S., Whitford, L. (1996). Factors affecting auditory performance of postlinguistically deaf adults using cochlear implants. Audiology and Neuro-Otology, 1(5), 293-306.

14. Staecker, H., Jolly, C., Garnham, C. (2010). Cochlear implantation: an opportunity for drug development. Drug Discovery Today, 15(7-8), 314-21.

15. Shepherd, RK., Coco, A., Epp, SB. (2008). Neurotrophins and electrical stimulation for protection and repair of spiral ganglion neurons following sensorineural hearing loss. Hearing Research, 242(1-2), 100-9.

16. Coleman, B., de Silva, MG., Shepherd, RK. (2007). Concise review: the potential of stem cells for auditory neuron generation and replacement. Stem cells 25(11), 2685-94. 

peripheral and central auditory systems. Hearing Research, 278(1-2), 2-20.

18. Shepherd, RK., Javel, E. (1997). Electrical stimulation of the auditory nerve. I. Correlation of physiological responses with cochlear status. Hearing Research, 108(1-2), 11244.

19. Shepherd, RK., Hardie, NA. (2001). Deafness-induced changes in the auditory pathway: implications for cochlear implants. Audiology and Neuro-Otology, 6(6), 305-18.

20. Hall, RD. (1990). Estimation of surviving spiral ganglion cells in the deaf rat using the electrically evoked auditory brainstem response. Hearing Research, 49(1-3), 155-68.

21. Sly, DJ., Heffer, LF., White, MW., Shepherd, RK., Birch, MG., Minter, RL., Nelson, NE., Wise, AK., O'Leary, SJ. (2007). Deafness alters auditory nerve fibre responses to cochlear implant stimulation. European Journal of Neuroscience, 26(2), 510-22.

22. Shepherd, RK., Roberts, LA., Paolini, AG. (2004). Long-term sensorineural hearing loss induces functional changes in the rat auditory nerve. European Journal of Neuroscience, 20(11), 3131-40.

23. Fayad, JN., Linthicum, FH, Jr. (2006). Multichannel cochlear implants: relation of histopathology to performance. Laryngoscope, 116(8), 1310-20.

24. Linthicum, FH, Jr.., Fayad, JN. (2009). Spiral ganglion cell loss is unrelated to segmental cochlear sensory system degeneration in humans. Otology and Neurotology, 30(3), 418-22.

25. Teufert, KB., Linthicum, FH, Jr.., Connell, SS. (2006). The effect of organ of corti loss on ganglion cell survival in humans. Otology and Neurotology, 27(8), 1146-51.

26. Rask-Andersen, H., Tylstedt, S., Kinnefors, A., Schrott-Fischer, A. (1997). Nerve fibre interaction with large ganglion cells in the human spiral ganglion: A TEM study. Auris, Nasus, Larynx, 24(1), 1-11.

27. Tylstedt, S., Rask-Andersen, H. (2001). A 3-D model of membrane specializations between human auditory spiral ganglion cells. Journal of Neurocytology, 30(6), 465-73.

28. Rubinstein, JT., Miller, CA. (1999). How do cochlear prostheses work? Current Opinion in Neurobiology, 9(4), 399-404.

29. Shibata, SB., Raphael, Y. (2010). Future approaches for inner ear protection and repair. Journal of Communication Disorders, 43(4), 295-310.

30. Hildebrand, MS., Dahl, HH., Hardman, J., Coleman, B., Shepherd, RK., de Silva, MG. (2005). Survival of partially differentiated mouse embryonic stem cells in the scala media of the guinea pig cochlea. Journal of the Association for Research in Otolaryngology, 6(4), 341-54.

31. Tateya, I., Nakagawa, T., Iguchi, F., Kim, TS., Endo, T., Yamada, S., Kageyama, R., Naito, Y., Ito, J. (2003). Fate of neural stem cells grafted into injured inner ears of mice. Neuroreport, 14(13), 1677-81.

32. Ito, J., Kojima, K., Kawaguchi, S. (2001). Survival of neural stem cells in the cochlea. Acta Otolaryngol, 121(2), 140-2.

33. Li, H., Roblin, G., Liu, H., Heller, S. (2003). Generation of hair cells by stepwise differentiation of embryonic stem cells. Proceedings of the National Academy of Sciences of the United States of America, 100(23), 13495-500.

34. Regala, C., Duan, M., Zou, J., Salminen, M., Olivius, P. (2005). Xenografted fetal dorsal root ganglion, embryonic stem cell and adult neural stem cell survival following implantation into the adult vestibulocochlear nerve. Experimental Neurology, 193(2), 326-33. 

Hiratsuka, Y., Tamura, T., Kanemaru, S., Shimizu, Y., Ito, J. (2004). Transplantation of bone marrow stromal cells into the cochlea of chinchillas. Neuroreport, 15(1), 1-4.

36. Matsumoto, M., Nakagawa, T., Kojima, K., Sakamoto, T., Fujiyama, F., Ito, J. (2008). Potential of embryonic stem cell-derived neurons for synapse formation with auditory hair cells. Journal of Neuroscience Research, 86(14), 3075-85.

37. Altschuler, RA., O'Shea, KS., Miller, JM. (2008). Stem cell transplantation for auditory nerve replacement. Hearing Research, 242(1-2), 110-6.

38. Olivius, P., Alexandrov, L., Miller, J., Ulfendahl, M., Bagger-Sjoback, D., Kozlova, EN. (2003). Allografted fetal dorsal root ganglion neuronal survival in the guinea pig cochlea. Brain Research, 979(1-2), 1-6.

39. Coleman, B., Hardman, J., Coco, A., Epp, S., de Silva, M., Crook, J., Shepherd, R. (2006). Fate of embryonic stem cells transplanted into the deafened mammalian cochlea. Cell Transplantation, 15(5), 369-80.

40. Ahn, KS., Jeon, SJ., Jung, JY., Kim, YS., Kang, JH., Shin, S., Choi, T., Choi, SJ., Chung, P., Shim, H. (2008). Isolation of embryonic stem cells from enhanced green fluorescent protein-transgenic mouse and their survival in the cochlea after allotransplantation. Cytotherapy, 10(7), 759-69.

41. Hu, Z., Wei, D., Johansson, CB., Holmstrom, N., Duan, M., Frisen, J., Ulfendahl, M. (2005). Survival and neural differentiation of adult neural stem cells transplanted into the mature inner ear. Experimental Cell Research, 302(1), 40-7.

42. Hu, Z., Andang, M., Ni, D., Ulfendahl, M. (2005). Neural cograft stimulates the survival and differentiation of embryonic stem cells in the adult mammalian auditory system. Brain Research, 1051(1-2), 137-44.

43. Hu, Z., Ulfendahl, M., Olivius, NP. (2004). Central migration of neuronal tissue and embryonic stem cells following transplantation along the adult auditory nerve. Brain Research, 1026(1), 68-73.

44. Parker, MA., Corliss, DA., Gray, B., Anderson, JK., Bobbin, RP., Snyder, EY., Cotanche, DA. (2007). Neural stem cells injected into the sound-damaged cochlea migrate throughout the cochlea and express markers of hair cells, supporting cells, and spiral ganglion cells. Hearing Research, 232(1-2), 29-43.

45. Lang, H., Schulte, BA., Goddard, JC., Hedrick, M., Schulte, JB., Wei, L., Schmiedt, RA. (2008). Transplantation of mouse embryonic stem cells into the cochlea of an auditoryneuropathy animal model: effects of timing after injury. Journal of the Association for Research in Otolaryngology, 9(2), 225-40.

46. Reyes, JH., O'Shea, KS., Wys, NL., Velkey, JM., Prieskorn, DM., Wesolowski, K., Miller, JM., Altschuler, RA. (2008). Glutamatergic neuronal differentiation of mouse embryonic stem cells after transient expression of neurogenin 1 and treatment with BDNF and GDNF: in vitro and in vivo studies. Journal of Neuroscience, 28(48), 12622-31.

47. Fu, Y., Wang, S., Liu, Y., Wang, J., Wang, G., Chen, Q., Gong, S. (2009). Study on neural stem cell transplantation into natural rat cochlea via round window. American Journal of Otolaryngology, 30(1), 8-16.

48. Nishimura, K., Nakagawa, T., Ono, K., Ogita, H., Sakamoto, T., Yamamoto, N., Okita, K., Yamanaka, S., Ito, J. (2009). Transplantation of mouse induced pluripotent stem cells into the cochlea. Neuroreport, 20(14), 1250-4. 
49. Matsuoka, AJ., Kondo, T., Miyamoto, RT., Hashino, E. (2007). Enhanced survival of bone-marrow-derived pluripotent stem cells in an animal model of auditory neuropathy. Laryngoscope, 117(9), 1629-35.

50. Corrales, CE., Pan, L., Li, H., Liberman, MC., Heller, S., Edge, ASB. (2006). Engraftment and differentiation of embryonic stem cell-derived neural progenitor cells in the cochlear nerve trunk: Growth of processes into the organ of corti. Journal of Neurobiology, 66(13), 1489-500.

51. Sekiya, T., Kojima, K., Matsumoto, M., Kim, TS., Tamura, T., Ito, J. (2006). Cell transplantation to the auditory nerve and cochlear duct. Experimental Neurology, 198(1), 12-24.

52. Shi, F., Corrales, CE., Liberman, MC., Edge, AS. (2007). BMP4 induction of sensory neurons from human embryonic stem cells and reinnervation of sensory epithelium. European Journal of Neuroscience, 26(11), 3016-23.

53. Iguchi, F., Nakagawa, T., Tateya, I., Kim, TS., Endo, T., Taniguchi, Z., Naito, Y., Ito, J. (2003). Trophic support of mouse inner ear by neural stem cell transplantation. Neuroreport, 14(1), 77-80.

54. Praetorius, M., Vicario, I., Schimmang, T. (2008). Efficient transfer of embryonic stem cells into the cochlea via a non-invasive vestibular route. Acta Otolaryngol, 128(7), 720-3.

55. Tamura, T., Nakagawa, T., Iguchi, F., Tateya, I., Endo, T., Kim, TS., Dong, Y., Kita, T., Kojima, K., Naito, Y., Omori, K., Ito, J. (2004). Transplantation of neural stem cells into the modiolus of mouse cochleae injured by cisplatin. Acta Otolaryngol Suppl, (551), 65-8.

56. Hildebrand, MS., Newton, SS., Gubbels, SP., Sheffield, AM., Kochhar, A., de Silva, MG., Dahl, HH., Rose, SD., Behlke, MA., Smith, RJ. (2008). Advances in molecular and cellular therapies for hearing loss. Molecular Therapy, 16(2), 224-36.

57. Sharif, S., Nakagawa, T., Ohno, T., Matsumoto, M., Kita, T., Riazuddin, S., Ito, J. (2007). The potential use of bone marrow stromal cells for cochlear cell therapy. Neuroreport, 18(4), 351-4.

58. Okano, T., Nakagawa, T., Endo, T., Kim, TS., Kita, T., Tamura, T., Matsumoto, M., Ohno, T., Sakamoto, T., Iguchi, F., Ito, J. (2005). Engraftment of embryonic stem cell-derived neurons into the cochlear modiolus. Neuroreport, 16(17), 1919-22.

59. Pandit, SR., Sullivan, JM., Egger, V., Borecki, AA., Oleskevich, S. (2011). Functional effects of adult human olfactory stem cells on early-onset sensorineural hearing loss. Stem Cells, 29(4), 670-7.

60. Liu, Q., Ye, J., Yu, H., Li, H., Dai, C., Gu, Y., Zhu, Y., Zhang, Z. (2010). Survivalenhancing of spiral ganglion cells under influence of olfactory ensheathing cells by direct cellular contact. Neuroscience Letters, 478(1), 37-41.

61. Olivius, P., Alexandrov, L., Miller, JM., Ulfendahl, M., Bagger-Sjoback, D., Kozlova, EN. (2004). A model for implanting neuronal tissue into the cochlea. Brain Research. Brain Research Protocols, 12(3), 152-6.

62. Hu, Z., Ulfendahl, M., Olivius, NP. (2004). Survival of neuronal tissue following xenograft implantation into the adult rat inner ear. Experimental Neurology, 185(1), 7-14.

63. Coleman, B., Fallon, JB., Pettingill, LN., de Silva, MG., Shepherd, RK. (2007). Auditory hair cell explant co-cultures promote the differentiation of stem cells into bipolar neurons. Experimental Cell Research, 313(2), 232-43.

64. Sun, SK., Dee, CT., Tripathi, VB., Rengifo, A., Hirst, CS., Scotting, PJ. (2007). Epibranchial and otic placodes are induced by a common Fgf signal, but their subsequent development is independent. Developmental Biology, 303(2), 675-86. 
65. Park, BY., Saint-Jeannet, JP. (2008). Hindbrain-derived Wnt and Fgf signals cooperate to specify the otic placode in Xenopus. Developmental Biology, 324(1), 108-21.

66. Anniko, M., Wikstrom, SO. (1984). Pattern formation of the otic placode and morphogenesis of the otocyst. American Journal of Otolaryngology, 5(6), 373-81.

67. Bok, J., Chang, W., Wu, DK. (2007). Patterning and morphogenesis of the vertebrate inner ear. International Journal of Developmental Biology, 51(6-7), 521-33.

68. Morsli, H., Choo, D., Ryan, A., Johnson, R., Wu, DK. (1998). Development of the mouse inner ear and origin of its sensory organs. Journal of Neuroscience, 18(9), 3327-35.

69. Raft, S., Nowotschin, S., Liao, J., Morrow, BE. (2004). Suppression of neural fate and control of inner ear morphogenesis by Tbx1. Development, 131(8), 1801-12.

70. Vitelli, F., Viola, A., Morishima, M., Pramparo, T., Baldini, A., Lindsay, E. (2003). TBX1 is required for inner ear morphogenesis. Human Molecular Genetics, 12(16), 2041-8.

71. Nichols, DH., Pauley, S., Jahan, I., Beisel, KW., Millen, KJ., Fritzsch, B. (2008). Lmx1a is required for segregation of sensory epithelia and normal ear histogenesis and morphogenesis. Cell and Tissue Research, 334(3), 339-58.

72. Koo, SK., Hill, JK., Hwang, CH., Lin, ZS., Millen, KJ., Wu, DK. (2009). Lmx1a maintains proper neurogenic, sensory, and non-sensory domains in the mammalian inner ear. Developmental Biology, 333(1), 14-25.

73. Cole, LK., Le Roux, I., Nunes, F., Laufer, E., Lewis, J., Wu, DK. (2000). Sensory organ generation in the chicken inner ear: contributions of bone morphogenetic protein 4, serrate1, and lunatic fringe. Journal of Comparative Neurology, 424(3), 509-20.

74. Kiernan, AE., Pelling, AL., Leung, KK., Tang, AS., Bell, DM., Tease, C., Lovell-Badge, R., Steel, KP., Cheah, KS. (2005). Sox2 is required for sensory organ development in the mammalian inner ear. Nature, 434(7036), 1031-5.

75. Mak, AC., Szeto, IY., Fritzsch, B., Cheah, KS. (2009). Differential and overlapping expression pattern of SOX2 and SOX9 in inner ear development. Gene Expression Patterns, 9(6), 444-53.

76. Zou, D., Silvius, D., Fritzsch, B., Xu, PX. (2004). Eya1 and Six1 are essential for early steps of sensory neurogenesis in mammalian cranial placodes. Development, 131(22), 5561-72.

77. Ma, Q., Chen, Z., del Barco Barrantes, I., de la Pompa, JL., Anderson, DJ. (1998). neurogenin 1 is essential for the determination of neuronal precursors for proximal cranial sensory ganglia. Neuron, 20(3), 469-82.

78. Raft, S., Koundakjian, EJ., Quinones, H., Jayasena, CS., Goodrich, LV., Johnson, JE., Segil, N., Groves, AK. (2007). Cross-regulation of Ngn1 and Math1 coordinates the production of neurons and sensory hair cells during inner ear development. Development, 134(24), 4405-15. 79. Koundakjian, EJ., Appler, JL., Goodrich, LV. (2007). Auditory neurons make stereotyped wiring decisions before maturation of their targets. Journal of Neuroscience, 27(51), 14078-88.

80. Yang, T., Kersigo, J., Jahan, I., Pan, N., Fritzsch, B. (2011). The molecular basis of making spiral ganglion neurons and connecting them to hair cells of the organ of Corti. Hearing Research, 278(1-2), 21-33.

81. Ma, Q., Anderson, DJ., Fritzsch, B. (2000). Neurogenin 1 null mutant ears develop fewer, morphologically normal hair cells in smaller sensory epithelia devoid of innervation. Journal of the Association for Research in Otolaryngology, 1(2), 129-43. 

differentiation in ear ganglia and regulates hair cell subtype development in the cochlea. PLoS ONE, 5(7), e11661.

83. Huang, EJ., Liu, W., Fritzsch, B., Bianchi, LM., Reichardt, LF., Xiang, M. (2001). Brn3a is a transcriptional regulator of soma size, target field innervation and axon pathfinding of inner ear sensory neurons. Development, 128(13), 2421-32.

84. Fritzsch, B. (2003). Development of inner ear afferent connections: forming primary neurons and connecting them to the developing sensory epithelia. Brain Research Bulletin, 60(5-6), 423-33.

85. Karis, A., Pata, I., van Doorninck, JH., Grosveld, F., de Zeeuw, CI., de Caprona, D., Fritzsch, B. (2001). Transcription factor GATA-3 alters pathway selection of olivocochlear neurons and affects morphogenesis of the ear. Journal of Comparative Neurology, 429(4), 61530 .

86. Jahan, I., Kersigo, J., Pan, N., Fritzsch, B. (2010). Neurod1 regulates survival and formation of connections in mouse ear and brain. Cell and Tissue Research, 341(1), 95-110.

87. Liu, M., Pereira, FA., Price, SD., Chu, MJ., Shope, C., Himes, D., Eatock, RA., Brownell, WE., Lysakowski, A., Tsai, MJ. (2000). Essential role of BETA2/NeuroD1 in development of the vestibular and auditory systems. Genes and Development, 14(22), 2839-54. 88. Zou, D., Erickson, C., Kim, EH., Jin, D., Fritzsch, B., Xu, PX. (2008). Eya1 gene dosage critically affects the development of sensory epithelia in the mammalian inner ear. Human Molecular Genetics, 17(21), 3340-56.

89. Dabdoub, A. (2008). Sox2 signaling in prosensory domain specification and subsequent hair cell differentiation in the developing cochlea. Proceedings of the National Academy of Sciences of the United States of America, 105(47), 18396.

90. Puligilla, C., Dabdoub, A., Brenowitz, SD., Kelley, MW. (2010). Sox2 induces neuronal formation in the developing mammalian cochlea. Journal of Neuroscience, 30(2), 714-22.

91. Hafidi, A., Despres, G., Romand, R. (1993). Ontogenesis of type II spiral ganglion neurons during development: peripherin immunohistochemistry. International Journal of Developmental Neuroscience, 11(4), 507-12.

92. Berglund, AM., Ryugo, DK. (1991). Neurofilament antibodies and spiral ganglion neurons of the mammalian cochlea. Journal of Comparative Neurology, 306(3), 393-408.

93. Fritzsch, B., Dillard, M., Lavado, A., Harvey, NL., Jahan, I. (2010). Canal cristae growth and fiber extension to the outer hair cells of the mouse ear require Prox1 activity. PLoS ONE, 5(2), e9377.

94. Lin, J., Ozeki, M., Javel, E., Zhao, Z., Pan, W., Schlentz, E., Levine, S. (2003). Identification of gene expression profiles in rat ears with cDNA microarrays. Hearing Research, 175(1-2), 2-13.

95. Chen, WC., Xue, HZ., Hsu, YL., Liu, Q., Patel, S., Davis, RL. (2011). Complex distribution patterns of voltage-gated calcium channel alpha-subunits in the spiral ganglion. Hearing Research, 278(1-2), 52-68.

96. Nayagam, BA., Minter, RL. (2011). A comparison of in vitro treatments for directing stem cells toward a sensory neural fate. American Journal of Otolaryngology, In press.

97. Lin, J., Feng, L., Hamajima, Y., Komori, M., Burns, TC., Fukudome, S., Anderson, J., Wang, D., Verfaillie, CM., Low, WC. (2009). Directed differentiation of mouse cochlear neural progenitors in vitro. American Journal of Physiology. Cell Physiology, 296(3), C441-52. 
98. Chen, W., Johnson, SL., Marcotti, W., Andrews, PW., Moore, HD., Rivolta, MN. (2009). Human fetal auditory stem cells can be expanded in vitro and differentiate into functional auditory neurons and hair cell-like cells. Stem Cells, 27(5), 1196-204.

99. Nayagam, BA., Edge, AS., Dottori, M. (2011). Stem cell-derived sensory progenitors can innervate the early post-natal sensory epithelium in vitro. Proceedings of the Association for Research in Otolaryngology. Pg 8.

100. Jiang, X., Gwye, Y., McKeown, SJ., Bronner-Fraser, M., Lutzko, C., Lawlor, ER. (2009). Isolation and characterization of neural crest stem cells derived from in vitrodifferentiated human embryonic stem cells. Stem Cells and Development, 18(7), 1059-70.

101. Lee, G., Kim, H., Elkabetz, Y., Al Shamy, G., Panagiotakos, G., Barberi, T., Tabar, V., Studer, L. (2007). Isolation and directed differentiation of neural crest stem cells derived from human embryonic stem cells. Nature Biotechnology, 25(12), 1468-75.

102. Pomp, O., Brokhman, I., Ziegler, L., Almog, M., Korngreen, A., Tavian, M., Goldstein, RS. (2008). PA6-induced human embryonic stem cell-derived neurospheres: a new source of human peripheral sensory neurons and neural crest cells. Brain Research, 1230, 50-60.

103. Hotta, R., Pepdjonovic, L., Anderson, RB., Zhang, D., Bergner, AJ., Leung, J., Pebay, A., Young, HM., Newgreen, DF., Dottori, M. (2009). Small-molecule induction of neural crestlike cells derived from human neural progenitors. Stem cells

27(12), 2896-905.

104. Taylor, KM., Labonne, C. (2005). SoxE factors function equivalently during neural crest and inner ear development and their activity is regulated by SUMOylation. Developmental Cell, 9(5), 593-603.

105. Saint-Germain, N., Lee, YH., Zhang, Y., Sargent, TD., Saint-Jeannet, JP. (2004). Specification of the otic placode depends on Sox9 function in Xenopus. Development, 131(8), 1755-63.

106. Fedtsova, NG., Turner, EE. (1995). Brn-3.0 expression identifies early post-mitotic CNS neurons and sensory neural precursors. Mechanisms of Development, 53(3), 291-304.

107. Huang, EJ., Zang, K., Schmidt, A., Saulys, A., Xiang, M., Reichardt, LF. (1999). POU domain factor Brn-3a controls the differentiation and survival of trigeminal neurons by regulating Trk receptor expression. Development, 126(13), 2869-82.

108. Silos-Santiago, I., Fagan, AM., Garber, M., Fritzsch, B., Barbacid, M. (1997). Severe sensory deficits but normal CNS development in newborn mice lacking TrkB and TrkC tyrosine protein kinase receptors. Eur J Neurosci, 9(10), 2045-56.

109. Henion, PD., Garner, AS., Large, TH., Weston, JA. (1995). trkC-mediated NT-3 signaling is required for the early development of a subpopulation of neurogenic neural crest cells. Developmental Biology, 172(2), 602-13.

110. Schecterson, LC., Bothwell, M. (1994). Neurotrophin and neurotrophin receptor mRNA expression in developing inner ear. Hear Res, 73(1), 92-100.

111. Schimmang, T., Minichiello, L., Vazquez, E., San Jose, I., Giraldez, F., Klein, R., Represa, J. (1995). Developing inner ear sensory neurons require TrkB and TrkC receptors for innervation of their peripheral targets. Development, 121(10), 3381-91.

112. Pirvola, U., Arumae, U., Moshnyakov, M., Palgi, J., Saarma, M., Ylikoski, J. (1994). Coordinated expression and function of neurotrophins and their receptors in the rat inner ear during target innervation. Hear Res, 75(1-2), 131-44. 
113. Minichiello, L., Piehl, F., Vazquez, E., Schimmang, T., Hokfelt, T., Represa, J., Klein, R. (1995). Differential effects of combined trk receptor mutations on dorsal root ganglion and inner ear sensory neurons. Development, 121(12), 4067-75.

114. Fritzsch B., Silos-Santiago I., Smeyne R., Fagan AM., M, B. (1995). Reduction and loss of inner ear innervation in trkB and trkC receptor knockout mice: a whole mount DiI and scanning electron microscopic analysis. Auditory neuroscience, 1, 401-17.

115. Takahashi, K., Yamanaka, S. (2006). Induction of pluripotent stem cells from mouse embryonic and adult fibroblast cultures by defined factors. Cell, 126(4), 663-76.

116. Liao, J., Cui, C., Chen, S., Ren, J., Chen, J., Gao, Y., Li, H., Jia, N., Cheng, L., Xiao, H., Xiao, L. (2009). Generation of induced pluripotent stem cell lines from adult rat cells. Cell Stem Cell, 4(1), 11-5.

117. Okita, K., Ichisaka, T., Yamanaka, S. (2007). Generation of germline-competent induced pluripotent stem cells. Nature, 448(7151), 313-7.

118. Li, W., Wei, W., Zhu, S., Zhu, J., Shi, Y., Lin, T., Hao, E., Hayek, A., Deng, H., Ding, S. (2009). Generation of rat and human induced pluripotent stem cells by combining genetic reprogramming and chemical inhibitors. Cell Stem Cell, 4(1), 16-9.

119. Jiang, P., Rushing, SN., Kong, CW., Fu, J., Lieu, DK., Chan, CW., Deng, W., Li, RA. (2010). Electrophysiological properties of human induced pluripotent stem cells. American Journal of Physiology. Cell Physiology, 298(3), C486-95.

120. Kawasaki, H., Mizuseki, K., Nishikawa, S., Kaneko, S., Kuwana, Y., Nakanishi, S., Nishikawa, SI., Sasai, Y. (2000). Induction of midbrain dopaminergic neurons from ES cells by stromal cell-derived inducing activity. Neuron, 28(1), 31-40.

121. Coleman, B., Backhouse, S., Shepherd, R. (2007). A targeted delivery strategy for the transplantation of stem cells into Rosenthal's canal. Proceedings of the Association for Research in Otolaryngology. 94

122. Sekiya, T., Holley, MC., Kojima, K., Matsumoto, M., Helyer, R., Ito, J. (2007). Transplantation of conditionally immortal auditory neuroblasts to the auditory nerve. European Journal of Neuroscience, 25(8), 2307-18.

123. Chen, W., Cacciabue-Rivolta, DI., Moore, HD., Rivolta, MN. (2007). The human fetal cochlea can be a source for auditory progenitors/stem cells isolation. Hearing Research, 233(12), 23-9.

124. Nicholl, AJ., Kneebone, A., Davies, D., Cacciabue-Rivolta, DI., Rivolta, MN., Coffey, P., Holley, MC. (2005). Differentiation of an auditory neuronal cell line suitable for cell transplantation. European Journal of Neuroscience, 22(2), 343-53.

125. MacLaren, RE., Pearson, RA., MacNeil, A., Douglas, RH., Salt, TE., Akimoto, M., Swaroop, A., Sowden, JC., Ali, RR. (2006). Retinal repair by transplantation of photoreceptor precursors. Nature, 444(7116), 203-7.

126. Backhouse, S., Coleman, B., Shepherd, R. (2008). Surgical access to the mammalian cochlea for cell-based therapies. Experimental Neurology, 214(2), 193-200.

127. Ryugo, DK., Rosenbaum, BT., Kim, PJ., Niparko, JK., Saada, AA. (1998). Single unit recordings in the auditory nerve of congenitally deaf white cats: morphological correlates in the cochlea and cochlear nucleus. Journal of Comparative Neurology, 397(4), 532-48.

128. Ryugo, DK., Kretzmer, EA., Niparko, JK. (2005). Restoration of auditory nerve synapses in cats by cochlear implants. Science, 310(5753), 1490-2. 
129. Ryugo, DK., Baker, CA., Montey, KL., Chang, LY., Coco, A., Fallon, JB., Shepherd, RK. (2010). Synaptic plasticity after chemical deafening and electrical stimulation of the auditory nerve in cats. Journal of Comparative Neurology, 518(7), 1046-63.

130. Fallon, JB., Irvine, DR., Shepherd, RK. (2009). Cochlear implant use following neonatal deafness influences the cochleotopic organization of the primary auditory cortex in cats. Journal of Comparative Neurology, 512(1), 101-14.

131. Beisel, K., Hansen, L., Soukup, G., Fritzsch, B. (2008). Regenerating cochlear hair cells: quo vadis stem cell. Cell and Tissue Research, 333(3), 373-9.

132. Boer, JC., Carney, KE., van der Zee, S. (2009). Differentiation of mouse embryonic stem cells into spiral ganglion neurons: a therapeutic approach to deafness. Journal of Neuroscience, 29(18), 5711-2.

133. Erdo, F., Buhrle, C., Blunk, J., Hoehn, M., Xia, Y., Fleischmann, B., Focking, M., Kustermann, E., Kolossov, E., Hescheler, J., Hossmann, KA., Trapp, T. (2003). Host-dependent tumorigenesis of embryonic stem cell transplantation in experimental stroke. Journal of Cerebral Blood Flow and Metabolism, 23(7), 780-5.

134. Ulfendahl, M., Hu, Z., Olivius, P., Duan, M., Wei, D. (2007). A cell therapy approach to substitute neural elements in the inner ear. Physiology and Behavior, 92(1-2), 75-9.

135. Polo, JM., Liu, S., Figueroa, ME., Kulalert, W., Eminli, S., Tan, KY., Apostolou, E., Stadtfeld, M., Li, Y., Shioda, T., Natesan, S., Wagers, AJ., Melnick, A., Evans, T., Hochedlinger, K. (2010). Cell type of origin influences the molecular and functional properties of mouse induced pluripotent stem cells. Nature Biotechnology, 28(8), 848-55.

136. Cantz, T., Martin, U. (2010). Induced Pluripotent Stem Cells: Characteristics and Perspectives. In: Kasper C, van Griensven M, Pörtner R, eds. Bioreactor Systems for Tissue Engineering II (pp. 107-26). Berlin: Springer.

137. Yamanaka, S. (2009). A fresh look at iPS cells. Cell, 137(1), 13-7. 
Click here to download Figure: Differentiation tree_June 2011.pptx

Type I

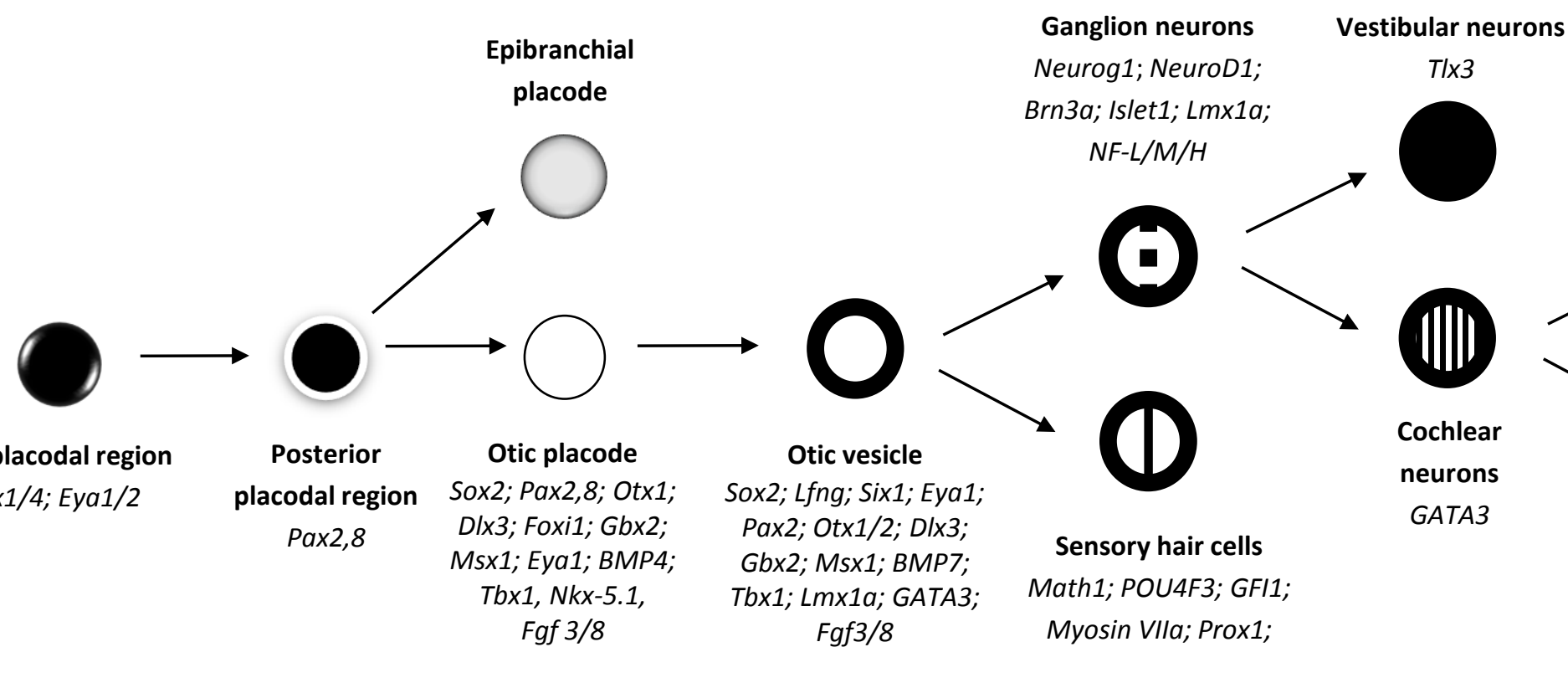

Ganglion neurons

Neurog1; NeuroD1;

Brn3a; Islet1; Lmx1a;

$N F-L / M / H$

Myosin VIIa; Prox 1 auditory neurons

GATA3; Ntrk2/3; Tlx 3;

VGLUT1/2; GluR2/3;

$N F-L / M / H$

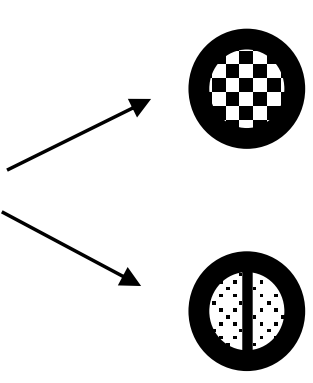

Type II

auditory neurons

GATA3; Peripherin;

NF-L/M/H (phosphorylated NFH within somata) 


\section{Figure}

Click here to download Figure: Fig2.ppt

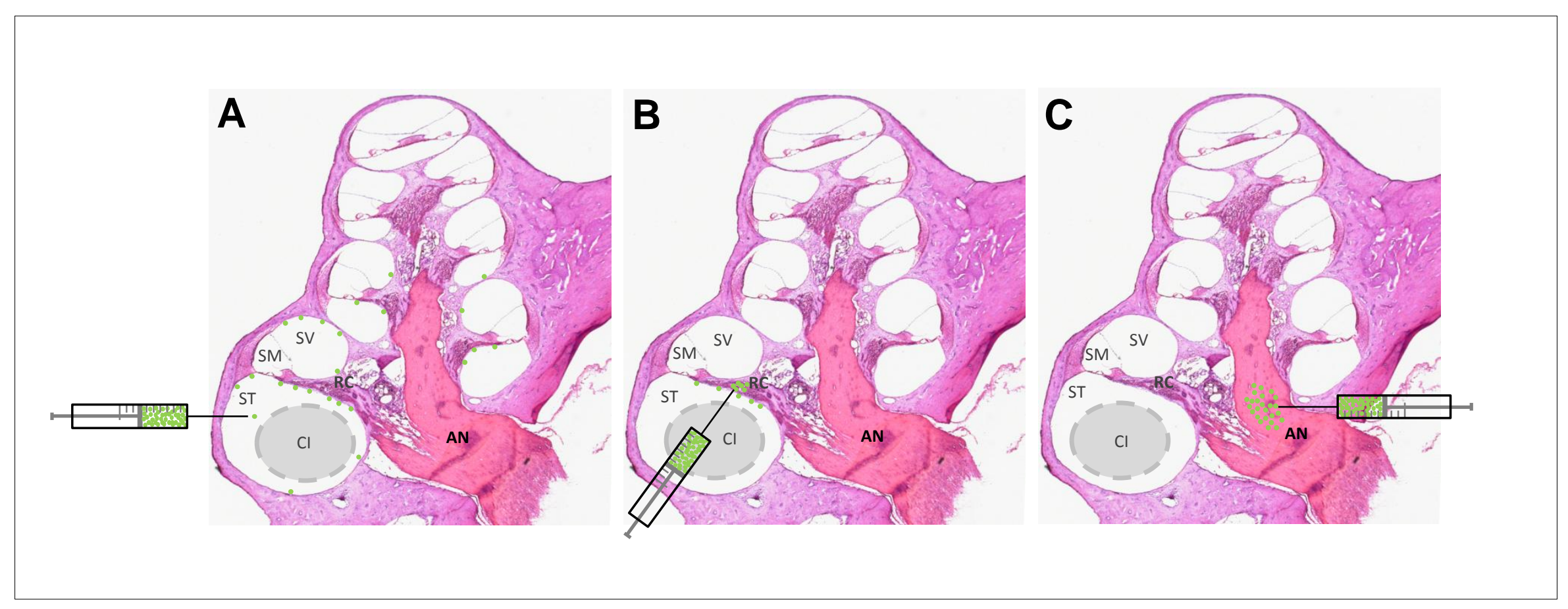

